\title{
Avaliação da resistência à compressão, resistência à tração e formação de microfissuras em concretos produzidos com diferentes tipos de cimentos, quando aplicado um pré-carregamento de compressão
}

Evaluation of compressive strength, tensile strength and microcracking formation in concretes produced with different cements, when a preloading of compression is applied

\section{Geilma Lima Vieira Denise Carpena Coitinho Dal Molin}

\section{Resumo

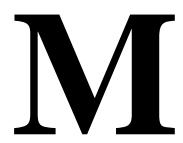

uitas empresas construtoras que querem competitividade no mercado buscam soluções para aumentar a velocidade de seus empreendimentos, tal como a redução do tempo de execução da estrutura, redução do tempo de escoramento e execução antecipada das alvenarias, sem respeitar o prazo mínimo de cura do concreto. A retirada precoce do escoramento submete a estrutura a uma carga prematura. Os danos causados pela incompleta reação de hidratação e cura do concreto podem desencadear um processo generalizado de formação de microfissuras. $\mathrm{O}$ presente estudo avaliou o comportamento de diferentes tipos de concretos produzidos com quatro diferentes tipos de cimentos, quando submetidos a uma carga precoce de compressão, analisando-se suas propriedades mecânicas. A análise incluiu a avaliação da resistência à compressão, resistência à tração e microestrutura interna do concreto, através de microscopia eletrônica de varredura. Os resultados indicaram que há possibilidade de um processo de formação de microfissuras causadas pelo carregamento precoce no concreto e que há tendência de diminuição dos valores de resistência à tração. Entretanto, verificou-se, mediante análise de microscopia, que as microfissuras formadas pelo carregamento precoce tendem a se recuperar se o processo de cura for retomado ou se cessar o pré-carregamento.

Palavras-chave: Concreto. Pré-carregamento. Resistência à compressão. Resistência à tração. Microfissuras.

\section{Abstract}

Many construction companies seeking competitive advantage in the market search for solutions to increase the speed of their projects, such as reducing the structure execution time, cutting shoring time and expediting the construction of masonry walls, disregarding the minimal time limit for curing concrete. Early withdrawal of the concrete structure shoring submits it to a premature load. The damage caused by incomplete hydration reaction and curing of the concrete can trigger a widespread process of formation of microcracks. This study examined the behavior of different types of concrete produced with four different types of cements, subjected to an early compressive load, analyzing their mechanical properties. The analysis included an evaluation of the compressive strength, tensile strength and internal microstructure of the concrete, using scanning electron microscopy. The results indicated that there is a possibility of forming microcracks due to preloading on concrete, and that there is a tendency of reaching lower tensile strength values. However, microscopic analysis showed that the microcracks formed by preloading tend to recover if either the curing process is resumed or if early loading stops.

Keywords: Concrete. Preload. Compressive strength. Tensile strength. Microcracking. 


\section{Introdução}

O processo de racionalização e industrialização da construção trouxe profundas alterações na forma de construir edificações no Brasil. O processo construtivo está modificado, assim como o cálculo estrutural e as técnicas gerenciais. Houve uma evolução da resistência do concreto, as estruturas e tipologias estão mais arrojadas e as alvenarias mais precisas. Além disso, têm surgido novos fenômenos, antes não observados nas construções e ainda pouco conhecidos pelos profissionais. Paredes de vedação estão se rompendo, fissuras nas alvenarias são visíveis e problemas nos revestimentos são cada vez mais frequentes. Fissuras e trincas em alvenaria originam-se devido ao mecanismo inerente que os materiais possuem de aliviar tensões que lhe são impostas. Fissuras de origem externa decorrem, em geral, da incompatibilidade entre estruturas de concreto armado e alvenarias de vedação. Essa incompatibilidade tem sido observada em função dos movimentos diferenciais entre os elementos de concreto armado e as paredes. A inadequação da sequência e velocidade de execução e a ausência de um projeto que considere corretamente a interação entre esses subsistemas na definição de materiais, detalhes de projeto e técnicas executivas podem ser apontadas como aspectos fundamentais nessa questão.

Entre as hipóteses assumidas e muitas vezes não verificadas que influenciam diretamente a deformação da estrutura estão: o módulo de elasticidade considerado no dimensionamento e não obtido em obra; o aumento da fluência e retração devido à velocidade de execução; e o carregamento e a diminuição da rigidez devido à microfissuração em trabalho.

Muitas empresas construtoras, para garantir competitividade no mercado, buscam soluções capazes de aumentar a velocidade de suas obras, tais como a redução do tempo de execução da estrutura e do período de escoramento, e antecipação do início das alvenarias, como pode ser observado na Figura 1. A retirada antecipada do escoramento submete a estrutura a um carregamento precoce, sem que haja tempo suficiente de ocorrerem todas as reações de hidratação do cimento, podendo desencadear um processo de microfissuração no concreto. Como consequência, as deformações instantâneas e lentas tendem a aumentar, podendo intensificar a incidência de manifestações patológicas nas edificações (MEDEIROS, 2005).

Pela Figura 1, o ciclo de concretagem é de 7 dias e só há dois jogos de escoramento (situação A). Nessa configuração, para os procedimentos de concretagem do terceiro pavimento (situação B), terá de ser deslocado o escoramento. Para essa situação terá de ser retirado o escoramento do primeiro pavimento (situação A), que está apenas com cura de 15 dias e que suportará, além do peso próprio, as cargas provenientes dos elementos superiores.

Cada elemento recém-concretado é suportado por outro, que, por sua vez, ainda não desenvolveu resistência suficiente para suportar as cargas adicionais. Aliado a isso, tem-se a execução antecipada das alvenarias (situação C), que é mais uma etapa construtiva e somatiza possíveis efeitos indesejáveis na estrutura como um todo, pois a cada etapa construtiva realizada nova parcela de ação é absorvida pelos elementos estruturais, curados ou não.

Sem resistência suficiente e escoramento permanente que possa suportar as cargas adicionais, podem ocorrer deformações não previstas em projetos em função desse ciclo de concretagem e disponibilidade insuficiente de escoramento. Tais deformações, não previstas, podem provocar o surgimento de fissuras em função dos esforços prematuros.
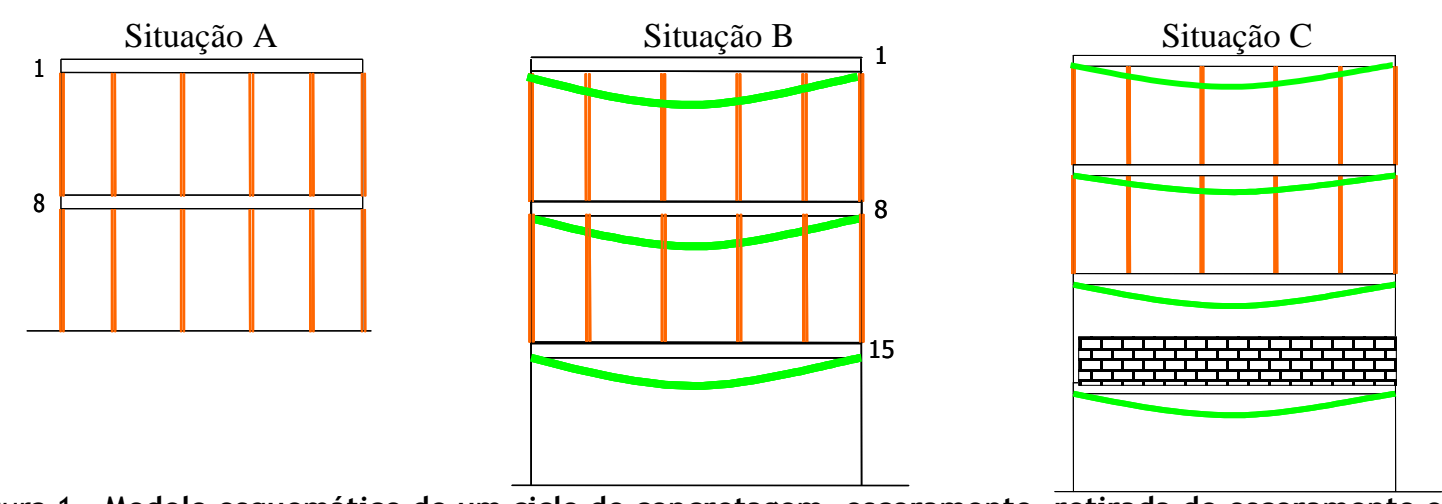

Figura 1 - Modelo esquemático de um ciclo de concretagem, escoramento, $\overline{\text { retirada de escoramento e }}$ execução de alvenaria de uma construção (a partir de Prado, 1999) 
As normas brasileiras vigentes (NBR 14931) não estabelecem prazos para a retirada de formas e escoramentos, mas indica que estes só podem ser removidos quando houver suficiente resistência do concreto para resistir às ações que atuarem sobre ele e não conduzir a uma configuração de deformações inaceitáveis, em função do baixo módulo de elasticidade do concreto e maior deformação diferida no tempo quando o concreto é solicitado com idades inferiores a 28 dias. A norma NBR 14931 (ABNT, 2003) recomenda que sejam atendidos os requisitos de monitoramento da gradual evolução da resistência do concreto nas primeiras idades

França (2005) aponta alguns fatores críticos que influenciam nas deformações de estruturas de concreto, entre elas a macroestrutura do concreto, os ciclos de execução e reescoramento. Uma solução eficaz, segundo o autor, é retardar o primeiro carregamento do concreto, ou seja, definir um cronograma de construção de modo a permitir que sejam asseguradas as resistências mecânicas do concreto (compressão, tração e módulo de elasticidade), assim como definir um bom projeto de reescoramento.

Além da tomada de decisão sobre os corretos procedimentos de cálculo, projeto e execução de estruturas de concreto, o conhecimento da tecnologia dos materiais constituintes do concreto pode ajudar a minimizar tais efeitos.

O desenvolvimento de novos materiais da construção civil e o conhecimento do desempenho das estruturas em um nível mais aprofundado surgem como parâmetros de grande importância na busca do melhor desempenho das estruturas dentro do processo de racionalização. Avaliação isolada de algumas propriedades como a resistência à compressão torna-se um parâmetro insuficiente no estudo do desempenho da estrutura quando submetida a cargas precoces. Nesse contexto, torna-se relevante o estudo de outras propriedades mecânicas (resistência à tração) do concreto, seus materiais constituintes, assim como suas fases de hidratação quando submetidos a um carregamento precoce, no sentido de garantir a segurança e o bom desempenho da estrutura ao longo do tempo.

\section{Comportamento mecânico do concreto sob carregamento de compressão}

No concreto, as tensões de tração induzidas pelas deformações na retração térmica e na secagem são grandes o suficiente para causar microfissuração na zona de transição, mesmo que o concreto não seja submetido a qualquer carga externa. A resistência à ruptura do elemento sob carga é controlada pela propagação e reunião de uma parte do sistema de microfissuras na pasta de cimento hidratada. De uma forma geral, a resistência do concreto aumenta com a idade enquanto as partículas não hidratadas de cimento continuam a formar produtos de hidratação, que tendem a reduzir o tamanho e o volume total de vazios. Genericamente, na faixa de relação água/aglomerante de 0,5 a 0,7 , pode-se dizer que a microestrutura da zona de transição impede o concreto de comportar-se como um material composto (AITCIN, 2000; NEVILLE, 1997).

É em função da presença da zona de transição que o concreto rompe a um nível de tensão consideravelmente mais baixo do que a resistência dos dois constituintes principais (agregado e pasta). Conforme comentado anteriormente, mesmo antes da aplicação do carregamento, já existem microfissuras na região da interface, que são geradas durante o processo de endurecimento da pasta e causadas pela exudação, retração por secagem, entre outros. A Figura 2 ilustra a evolução da fissuração nessa interface, sob condições de carregamento.

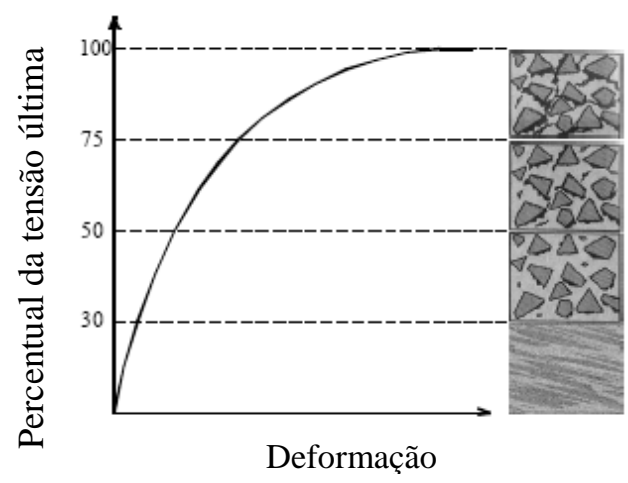

Figura 2 - Evolução da fissuração na interface entre a pasta e o agregado para concreto sob compressão uniaxial

Fonte: Mehta e Monteiro, 1994. 

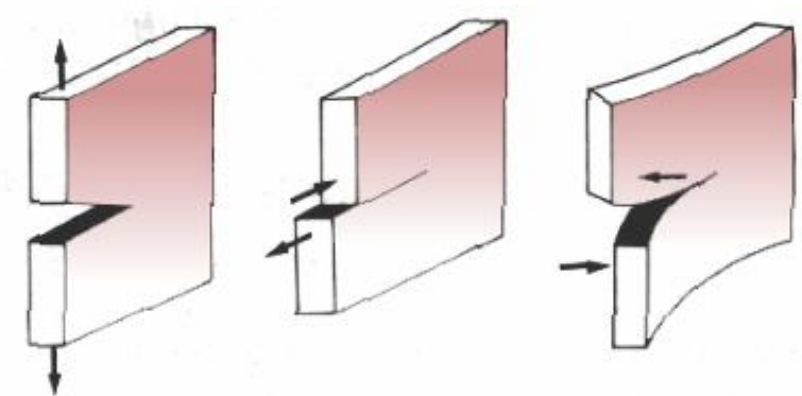

Figura 3 - Modos de solicitação e formação de fissura

Fonte: Santos, Souza e Bittencourt (2003).

Em níveis não muito elevados de energia para estender as fissuras já existentes na zona de transição, com tensões de $40 \%$ a $70 \%$ da resistência última, já se percebem incrementos de deformação por unidade de força aplicada. Em níveis de tensões maiores do que $70 \%$ da carga última, já se formam novas fissuras, propagandose gradativamente até se unirem às fissuras da zona de transição. Esse fato pode levar o material à ruptura. Sob cargas de tração, as fissuras se propagam a um nível muito mais baixo. Em relação ao módulo de elasticidade, a estrutura da zona de transição, principalmente o volume de vazios considerado e a presença de microfissuras, provoca grande interferência. No concreto, a zona de transição serve de ponte entre a matriz e o agregado graúdo. Mesmo que os materiais constituintes (argamassa e agregado graúdo) possuam elevada rigidez, a rigidez do material composto pode ser baixa em função da presença dos vazios e das microfissuras presentes na zona de transição, as quais não permitem transferência de resistência (MEHTA; MONTEIRO, 1994).

Quando um corpo de prova de concreto é submetido a um carregamento de compressão axial, a curva tensão-deformação apresenta um ramo ascendente, seguido por um pico que é conhecido como a resistência à compressão do concreto, como pôde ser visto na Figura 2. Embora a parte inicial da curva pareça uma reta, medições mais detalhadas mostram que existe uma curvatura desde o início do carregamento, em função dos processos de retração e endurecimento do cimento. Com isso surgem concentrações de tensões de tração na interface entre agregados e a pasta de cimento, causando microfissuras que podem se propagar quando estiverem sujeitas a carregamentos externos.

Uma importante classificação para o estudo de uma fissura ou trinca é o modo como ela está solicitada. Existem três modos possíveis, conforme se pode observar na Figura 3. O modo I é caracterizado por um esforço de tração unidirecional, com a fissura se desenvolvendo num plano perpendicular ao do carregamento. $\mathrm{O}$ modo II caracteriza-se pelo escorregamento entre as faces das fissuras, com esforço cisalhante aplicado na direção paralela ao defeito. O modo III também se caracteriza por escorregamento entre as faces, mas com esforço cisalhante atuando na direção perpendicular à da fissura. Esses são os modos de solicitação; qualquer outro constitui uma superposição desses aqui apresentados (BOTTA, 1998; KANG; BITTENCOURT, 1999; SANTOS, SOUZA; BITTENCOURT, 2003).

De acordo com Botta (1998), análises da danificação do concreto sob compressão permitem concluir que de $0 \%$ a $30 \%$ ou $40 \%$ da tensão máxima do ensaio uniaxial as fissuras permanecem estáveis na região da interface. Desse ponto até $70 \%$ ou $80 \%$ da carga máxima as fissuras se desenvolvem segundo os modos II (fissuras a $45^{\circ}$ em relação à direção da carga) e I, ainda na região da interface agregado-argamassa. A partir daí ocorre instabilidade e rupturas locais na argamassa, conduzindo o material à iminente ruptura devido à intensa degradação.

Em compressão uniaxial a danificação tem as características indicadas na Figura 4. A primeira fissura aparece com modo II de abertura na região do contorno do agregado, aproximadamente a $30^{\circ}$ em relação à horizontal. A fissura progride ao longo da interface, passando a apresentar um modo I de abertura. Em seguida, sua evolução se dá na direção da solicitação, deixando a região da interface para se propagar na matriz. Para elevados níveis de solicitação evidencia-se um panorama de fissuras paralelas à direção do carregamento (PITUBA, 2003; MAZARS; BAZANT, 1989). 


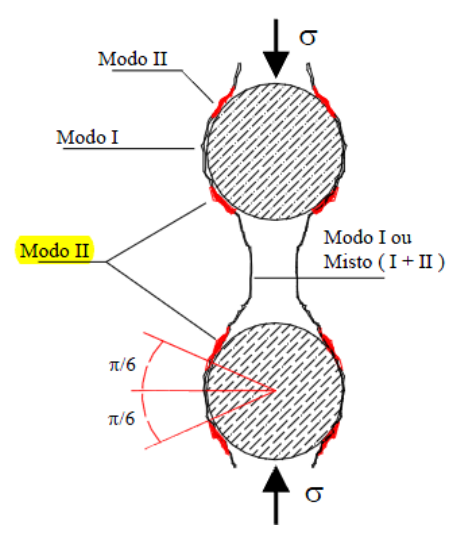

Figura 4 - Danificação sob solicitação de compressão com início na zona de transição (a partir de PITUBA, 2003)
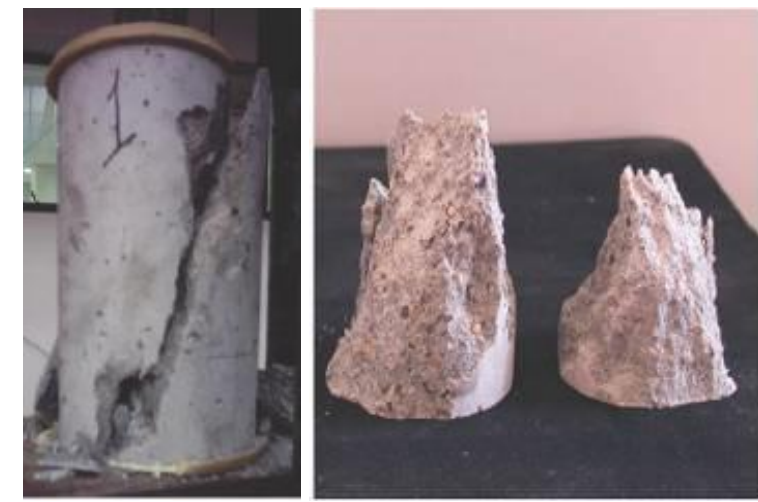

Figura 5 - Modos de ruptura do concreto submetido a carregamento de compressão - (a) plano de cisalhamento a $45^{\circ}$ e (b) ruptura em forma de cone

Fonte: Elaqra et al. (2007).

Dessa forma, a ruptura ocorre ortogonalmente à direção da carga aplicada, como no ensaio de tração por compressão diametral. Há grande possibilidade de que não exista uma tensão-limite, mas uma deformação-limite por tração, que determina a resistência do concreto sob solicitação estática. A ruptura final sob ação de uma compressão uniaxial é uma ruptura por tração de grãos de cimento ou uma ruptura da aderência em uma direção perpendicular à carga aplicada, ou, ainda, a ruína causada pelo surgimento de planos inclinados de cisalhamento. Por esse motivo explica-se a ruptura em forma de cone e com planos cisalhantes a $45^{\circ}$ em corpos de prova de concreto de formato cilíndricos. A Figura 5 apresenta exemplos dessa forma de ruptura (MAZARS; BAZANT, 1989; LANDIS; NAGY; KEANE, 2003; NEVILLE, 1997).

\section{Metodologia Experimental}

Os concretos produzidos foram ensaiados em quatro níveis de pré-carregamento de compressão $(0 \%, 25 \%, 50 \%$ e $75 \%$ em relação à carga de ruptura), aplicados aos 1, 3 e 7 dias de idade, utilizando-se diferentes relações água/cimento
$(0,35,0,50$ e 0,70$)$. Os concretos submetidos ao pré-carregamento foram ensaiados em diferentes idades, inclusive aos 28 dias, que é a idade de ensaio e parâmetro de referência da maioria dos projetos estruturais. Buscou-se verificar a influência da microfissuração na resistência à compressão axial, na resistência à tração e na formação de microfissuras dos diferentes tipos de concretos produzidos. Foram utilizados quatro tipos diferentes de cimentos (CPV ARI, CPV ARI RS, CPIV RS e CPII Z) com o objetivo de verificar a influência de suas diferentes composições e seu desempenho sob carregamento de compressão nas primeiras idades de cura e hidratação.

Os ensaios de resistência à compressão axial foram executados de acordo com os procedimentos da NBR 5739 (ABNT, 1994) - “Concreto - Ensaio de compressão de corpos-de-prova cilíndricos Método de ensaio", no que se refere à velocidade de carregamento, equipamento e preparação das amostras, nas idades predeterminadas no programa experimental. Os corpos de prova permaneceram em câmara úmida até a idade do ensaio. Também, na idade de 1, 3 e 7 dias, os corpos de prova foram capeados com enxofre para aplicação do pré- 
carregamento. Após o pré-carregamento, os corpos de prova retornavam à câmara úmida, permanecendo lá até a idade de 28 dias, para a execução dos ensaios.

A execução do ensaio de resistência à tração por compressão diametral seguiu as especificações da NBR 7222 (ABNT, 1994) - "Argamassa e concreto - Determinação da resistência à tração por compressão diametral de corpos-de-prova cilíndricos". Os corpos de prova permaneceram em câmara úmida até a idade de pré-carregamento e dos ensaios previstos. A execução do ensaio de tração por compressão diametral pode ser visto na Figura 6.

$\mathrm{Na}$ produção dos concretos foi adotado o procedimento de dosagem IPT/EPUSP. A Tabela 1 mostra os valores dos traços unitários, consumo de cimento $/ \mathrm{m}^{3}$, a média dos abatimentos obtidos, assim como os valores de temperatura e umidade relativa na etapa de execução e moldagem dos concretos.

Após a moldagem dos corpos de prova de acordo com a NBR 5738 (ABNT, 1994), os concretos permaneceram em um local protegido para evitar a saída de água por evaporação nas primeiras 24 horas. Após esse período, os corpos de prova foram desmoldados, identificados e mantidos em câmara úmida com umidade relativa superior a $95 \%$ e temperatura de $23 \pm 2{ }^{\circ} \mathrm{C}$, até as idades de ensaios.

A velocidade de aplicação do carregamento ao longo dos ensaios foi mantida constante para todos os percentuais de cargas. Ficou estabelecida uma taxa de $200 \mathrm{kN} / \mathrm{min}$ (aproximadamente 0,50 $\mathrm{MPa} / \mathrm{s})$. A Figura 6 apresenta a execução do précarregamento na prensa. Os ensaios de précarregamento foram realizados no Laboratório de Ensaios e Modelos Estruturais (LEME) da Universidade Federal do Rio Grande do Sul. Após o pré-carregamento, os corpos de prova retornavam ao ambiente de cura até a idade de ensaio.

\section{Resultados e discussão}

$\mathrm{Na}$ avaliação dos resultados de resistência à compressão e resistência à tração por compressão diametral foi realizado um tratamento estatístico para análise de significância das variáveis envolvidas nos ensaios (idade, relação água/cimento, porcentagem de carregamento, idade de carregamento) para os diferentes tipos de cimento. Foram desenvolvidos modelos de regressão linear múltipla para as variáveis de resposta (resistência à compressão e resistência à tração) medidas.

Os valores de resistência à compressão e de resistência à tração por compressão diametral obtidos pelo modelo são expressos sob a forma de gráficos de comportamento dos concretos produzidos em função das variáveis relação água/cimento (ac), idade, percentual de précarregamento (carregam) e idade de carregamento (idadecar).

Tabela 1 - Dosagem experimental

\begin{tabular}{ccccccc}
\hline Cimento & Relação a/c & $\begin{array}{c}\text { Consumo de } \\
\text { cimento/m }^{\mathbf{3}}\end{array}$ & $\begin{array}{c}\text { Traço } \\
\text { unitário }\end{array}$ & $\begin{array}{c}\text { Abatimento } \\
(\mathbf{c m})\end{array}$ & $\begin{array}{c}\text { Temperatura } \\
\left(\mathbf{}^{\mathbf{}} \mathbf{C}\right)\end{array}$ & $\begin{array}{c}\text { Umidade } \\
(\mathbf{\%})\end{array}$ \\
\hline \multirow{2}{*}{ CPII Z } & 0,35 & 627 & $1: 0,77: 1,63$ & 12,0 & 16,2 & 74 \\
& 0,50 & 357 & $1: 1,68: 2,47$ & 20,0 & 16,0 & 74 \\
& 0,70 & 257 & $1: 2,89: 3,59$ & 18,0 & 15,0 & 78 \\
\hline \multirow{2}{*}{ CPIV } & 0,35 & 604 & $1: 0,68: 1,49$ & 4,6 & 20,0 & 89 \\
RS & 0,50 & 360 & $1: 1,68: 2,38$ & 13,0 & 15,0 & 70 \\
& 0,70 & 255 & $1: 3,00: 3,55$ & 12,5 & 16,4 & 80 \\
\hline \multirow{2}{*}{ CPV } & 0,35 & 627 & $1: 0,98: 1,75$ & 7,0 & 20,0 & 68 \\
ARI & 0,50 & 374 & $1: 2,09: 2,74$ & 13,5 & 15,0 & 95 \\
& 0,70 & 261 & $1: 3,56: 4,05$ & 5,5 & 22,0 & 52 \\
\hline \multirow{2}{*}{ CPV } & 0,35 & 624 & $1: 0,95: 1,79$ & 5,0 & 24,0 & 60 \\
ARI RS & 0,50 & 368 & $1: 1,95: 2,73$ & 11,0 & 26,0 & 65 \\
\hline
\end{tabular}



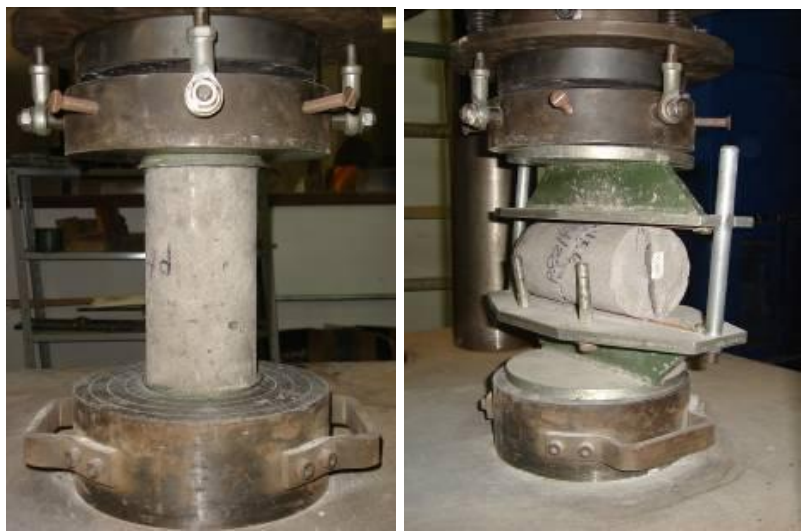

Figura 6 - (a) Aplicação do carregamento de compressão no corpo de prova e (b) ensaio de tração por compressão diametral

Tabela 2 - Modelo de regressão linear para cada tipo de cimento na propriedade de resistência à compressão

\begin{tabular}{|c|c|c|}
\hline Cimento & Modelo matemático & $\left(\mathbf{R}^{2}\right)$ \\
\hline CPII Z & $f c=-19,08+\frac{15,43}{a c}+0,42 \times i d a d e-\frac{0,56}{\sqrt{\text { carregam }^{2} \times \text { idadecar }^{2}}}-\frac{0,24 \times \text { idadecar }}{a c^{2}}$ & 95,49 \\
\hline $\begin{array}{c}\text { CPIV } \\
\text { RS }\end{array}$ & $f_{c}=-15,37+\frac{15,98}{a c}+0,43 \times$ idade $+\frac{0,027 \times \text { carregam }}{\sqrt{a c}}-1,22 \times$ idadecar $\times a c^{2}-\frac{0,061 \times \text { carregam }}{\text { idadecar }}$ & 97,12 \\
\hline $\begin{array}{l}\text { CPV } \\
\text { ARI }\end{array}$ & $f c=-13,27+\frac{18,40}{a c}+0,37 \times$ idade $+\frac{0,045 \times \text { carregam }}{\sqrt{a c}}-1,66 \times$ idadecar $\times a c^{2}-\frac{0,058 \times \text { carregam }}{i \text { idadecar }}$ & 98,00 \\
\hline $\begin{array}{l}\text { CPV } \\
\text { ARI } \\
\text { RS }\end{array}$ & $f c=-7,61+\frac{13,28}{a c}+0,61 \times$ idade $-0,789 \times$ idade $\times a c^{2}+\frac{0,006 \times \text { carregam }}{a c^{2}}+0,695 *$ idadecar $\times \sqrt{a c}$ & 91,15 \\
\hline
\end{tabular}

Fc: resistência à compressão axial, em Mpa;

a/c: relação água/cimento;

idade: idade do ensaio dos corpos de prova, em dias;

carregam: percentual de pré-carregamento (\%); e

idadecar: idade do pré-carregamento, em dias.

Na Tabela 2 é possível verificar que os modelos matemáticos de regressão linear múltipla ajustados para observar o comportamento da resistência à compressão em função das variáveis citadas possuem coeficientes de determinação $\left(\mathrm{R}^{2}\right)$ estão todos acima de $95 \%$. Isso significa que os modelos matemáticos desenvolvidos explicam mais de $95 \%$ da variabilidade dos resultados dos ensaios e, portanto, são confiáveis.

A Figura 7 apresenta os gráficos do efeito da interação entre o percentual de pré-carregamento e a relação $\mathrm{a} / \mathrm{c}$ sobre a resistência à compressão do concreto, para cada tipo de cimento. Ao contrário do que se esperava, houve aumento da resistência à medida que aumentava o percentual de précarregamento. $\mathrm{O}$ processo de formação de microfissuras através da resistência à compressão não pode ser explicado simplesmente por critérios de observação macroscópica. No entanto, algumas observações podem ser feitas a respeito desse comportamento.
Nas primeiras idades, apesar do baixo grau de hidratação, alguns cimentos já possuem uma estrutura interna razoavelmente formada, com compostos capazes de formar uma grande quantidade de etringita e, consequentemente, silicatos hidratados de cálcio $(\mathrm{CSH})$. Além disso, ocorre a formação de cristais orientados de hidróxido do cálcio $\left(\mathrm{CaOH}_{2}\right)$, que têm seu tamanho diretamente proporcional à porosidade do concreto. Esses produtos cristalinos consistem de cristais relativamente grandes e formam uma estrutura mais porosa na região da zona de transição. Quando o concreto recebe um précarregamento, possivelmente ocorre um efeito de compactação da estrutura, expulsando a água contida nos poros capilares e quebrando os cristais de hidróxido de cálcio, além de outros cristais mais fracos. Com isso, a estrutura interna do material se rearranja, liberando a área antes ocupada pelo hidróxido de cálcio e preenchendo os vazios formados com produtos resistentes remanescentes, provavelmente com hidratação de compostos anidros. 


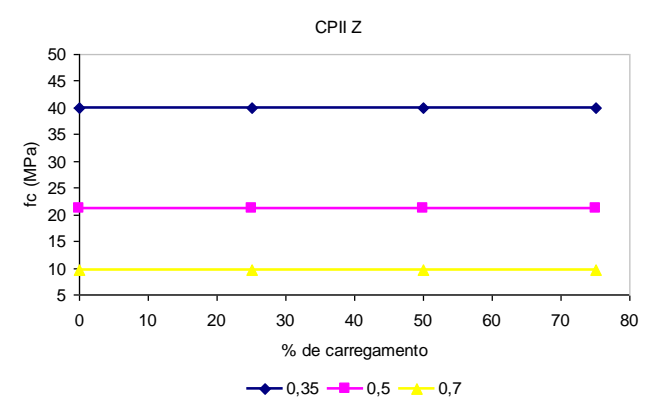

(a)

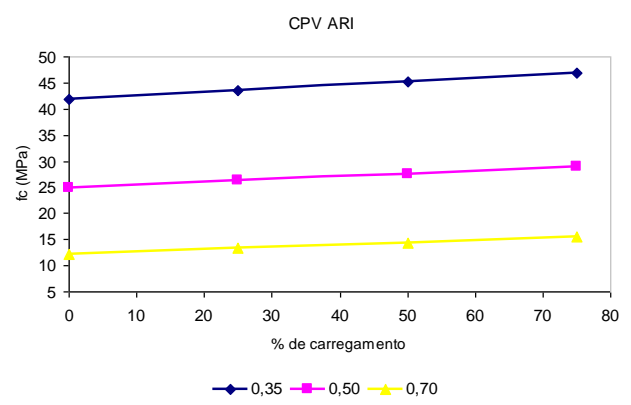

(c)

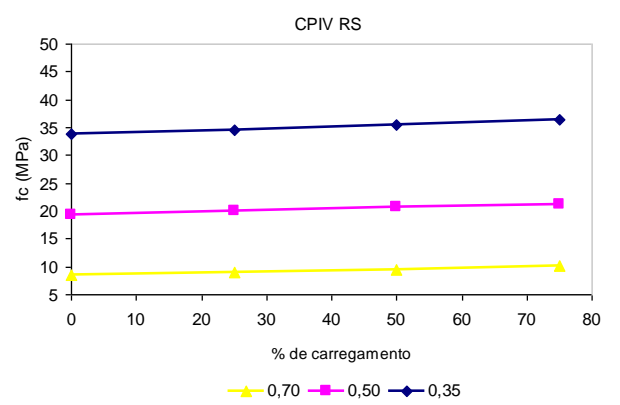

(b)

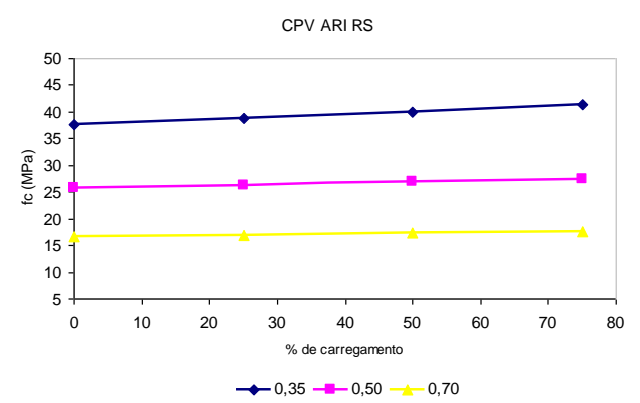

(d)

Figura 7 - Efeito da interação entre o percentual de carregamento e relação a/c sobre a resistência à compressão

Nota: (a) CPII Z; (b) CPIV RS; (c) CPV ARI; (d) CPV ARI RS.

Com o progresso da hidratação, o $\mathrm{CSH}$ remanescente e uma segunda geração de cristais menores de etringita e hidróxido de cálcio começam a preencher os espaços vazios deixados pelos cristais grandes de hidróxido de cálcio, ajudando a aumentar a densidade e, consequentemente, a resistência do material. Por esse motivo, explica-se o maior ganho de resistência para relações a/c menores.

Nas relações a/c maiores a resistência no concreto é explicada como uma consequência natural do progressivo enfraquecimento da matriz devido ao aumento da porosidade. Como não há quantidade suficiente de compostos resistentes remanescentes, ocorre apenas a quebra dos cristais de hidróxido de cálcio. Ainda assim o efeito é benéfico, uma vez que o carregamento quebra os cristais mais fracos, reorganizando a estrutura e tornando-a mais compacta.

Burlion, Bourgeois e Shao (2005) realizaram experimentos em testemunhos de concreto confinando o corpo de prova numa direção, deixando livre a outra direção e aplicando uma força de compressão no lado confinado. Os autores afirmam que a pressão exercida num corpo de prova de concreto provoca um confinamento da estrutura do concreto na direção de aplicação da carga e com isso induz a um aumento da resistência. Isso ocorre, segundo os autores, porque a pressão de confinamento provoca uma diminuição dos espaços intersticiais da composição da mistura. Quando os corpos de prova submetidos a cargas ficam expostos a um ambiente úmido, a água tende a percolar os interstícios formados pelas microfissuras, hidratando compostos químicos que ainda não se hidrataram, e, assim, proporciona um aumento da resistência. Os autores observaram aumento da resistência da ordem de até $15 \%$.

Na Figura 7 são mostrados os gráficos com o efeito da interação entre a idade em que o concreto foi pré-carregado e a relação a/c. Os valores da resistência à compressão foram obtidos por meio das equações de regressão linear obtidas para cada tipo de cimento.

Os gráficos da Figura 8 indicam que nos cimentos de reações de hidratação mais lentas, como o CPII $\mathrm{Z}$, por exemplo, o ganho de resistência foi maior em todas as relações $\mathrm{a} / \mathrm{c}$ à medida que aumentava $\mathrm{a}$ idade de pré-carregamento. Tal fato se deve, provavelmente, à evolução do processo de hidratação, o que não ocorreu com os cimentos de alta resistência inicial, em que o aumento de idade de pré-carregamento provoca pouca influência no ganho da resistência à compressão.

Cada um dos tipos de cimento Portland apresenta uma velocidade de hidratação diferente. Quanto mais fino o cimento, mais rápida é a evolução da resistência do concreto. Comparando a matriz do concreto de um cimento de alta resistência inicial 
com a de outro cimento comum, a baixas idades, a primeira matriz será muito menos porosa. Ao longo do tempo, os poros da matriz do cimento comum são preenchidos pelos produtos de hidratação, e a porosidade final poderá ser a mesma do concreto de alta resistência inicial. Portanto, a influência do tipo de cimento é mais significativa para baixas idades. $\mathrm{O}$ cimento de alta resistência inicial (ARI) possui um índice de finura maior que os outros tipos, o que explica o comportamento de maior resistência nas primeiras idades (NEVILLE, 1997).

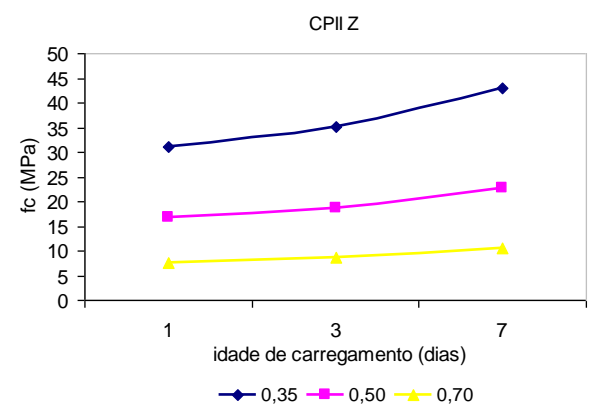

(a)

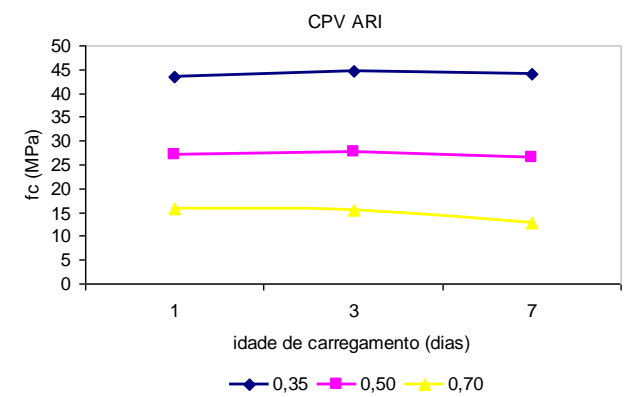

(c)

\section{Resistência à tração}

Para a análise da resistência à tração foi desenvolvido um modelo matemático através da análise de regressão múltipla, considerando todas as variáveis (relação a/c, idade de ensaio, idade de pré-carregamento e percentual de précarregamento). Assim como na resistência à compressão, na avaliação da resistência à tração por compressão diametral foi desenvolvido um modelo matemático para cada tipo de cimento.

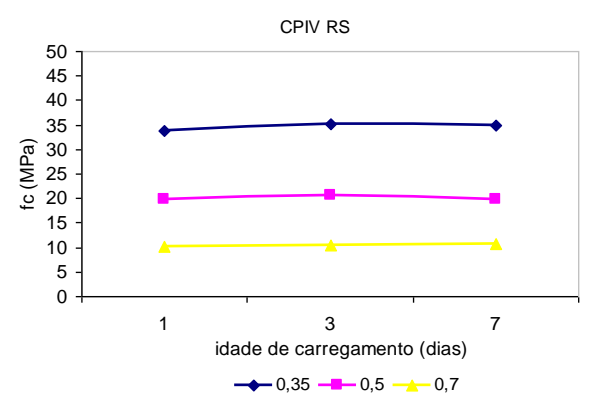

(b)

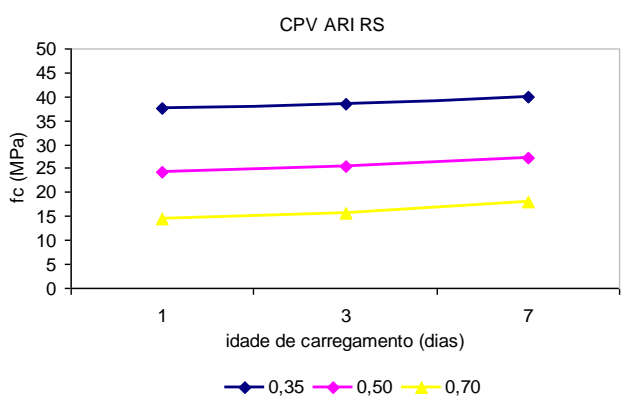

(d)

Figura 8 - Interação entre idade de carregamento e relação a/c sobre a resistência à compressão Nota: (a) CPIIZ; (b) CPIV RS; (c) CPV ARI; (d) CPV ARI RS.

Tabela 3 - Modelo de regressão linear para cada tipo de cimento na propriedade de resistência à tração por compressão diametral

\begin{tabular}{|c|c|c|}
\hline Cimento & Modelo matemático & $\left(\mathbf{R}^{2}\right)$ \\
\hline CPII Z & $f_{t^{\prime} D}=-0,488+\frac{1,00}{a c}-\frac{1,620}{i d a d e}+0,012 \times i d a d e \times \sqrt{\text { idadecar }}+\frac{5,11}{\text { carregam }}-0,038 \times a^{2} \times$ idadecar $^{2}$ & 93,38 \\
\hline $\begin{array}{l}\text { CPIV } \\
\text { RS }\end{array}$ & $f_{t^{\prime} D}=-1,314+\frac{1,443}{a c}+0,019 \times i d a d e+0,107 \times$ idadecar $-\frac{0,004 \times \text { idadecar }^{2}}{a c^{2}}-\frac{0,004}{a c^{3} \times \sqrt{\text { carregam }^{2}}}$ & 87,07 \\
\hline $\begin{array}{l}\text { CPV } \\
\text { ARI }\end{array}$ & $f_{t^{\prime} D}=2,416+\frac{0,288}{a c}-\frac{7,580 \times a c^{2}}{i d a d e^{2}}-\frac{0,760}{\text { idadecar }}+\frac{0,0788 \times \sqrt{\text { carregam }}}{\text { idadecar }}-0,4598 \times a c^{3} \times \sqrt{\text { carregam }}$ & 92,48 \\
\hline $\begin{array}{l}\text { CPV } \\
\text { ARI RS }\end{array}$ & $f_{t^{\prime} D}=-0,728+\frac{1,2111}{a c}+0,1452 \times$ idade $+0,1139 \times$ idadecar $-\frac{0,0803 \times \text { idade }}{a c}+0,0332 \times \sqrt{\text { carregam }}$ & 94,93 \\
\hline $\begin{array}{l}\text { Nota: } \\
\mathrm{f}_{\mathrm{t}^{\prime} \mathrm{D}}: \\
\mathrm{a} / \mathrm{c}: \\
\text { idad } \\
\text { carre } \\
\text { idad }\end{array}$ & $\begin{array}{l}\text { istência à tração por compressão diametral, em Mpa; } \\
\text { lação água/cimento; } \\
\text { idade do ensaio dos corpos de prova, em dias; } \\
\text { am: percentual de pré-carregamento (\%); e } \\
\text { ar: idade do pré-carregamento, em dias. }\end{array}$ & \\
\hline
\end{tabular}


Na Figura 9 é apresentado o efeito isolado do percentual de pré-carregamento sobre a resistência à tração do concreto.

Diferentemente do que apontou a resistência à compressão, não foram observados aumentos da resistência à tração à medida que se aumentava o percentual de carga, o que pode induzir a um possível estado de microfissuração. $\mathrm{O}$ efeito de colmatação das microfissuras ficou evidente para a resistência à compressão, mas para resistência à tração há indícios de que a recuperação das microfissuras não ocorre totalmente. Esse processo vai depender da quantidade de material anidro remanescente disponível, da quantidade de microfissuras formadas e abertas. Além disso, quando o concreto é submetido a um carregamento de compressão, a direção e a propagação das microfissuras tendem a se distribuir perpendicularmente à direção do carregamento, o que prejudica fortemente a resistência à tração. Apesar do aumento da resistência à compressão, provavelmente originada por uma resistência residual, o pré-carregamento não implicou o aumento da resistência à tração.

$\mathrm{O}$ efeito da interação entre o percentual de précarregamento e a relação a/c é apresentado na Figura 10. Os valores foram determinados a partir das equações obtidas nas modelagens de regressão linear da Tabela 3.

Na Figura 10 observa-se que a relação a/c tem influência direta no percentual de carregamento. Com o aumento do percentual de carga ocorre uma diminuição da resistência à tração, principalmente para relações a/c maiores e principalmente para o CPV ARI. Para o CPIV RS, os valores permanecem inalterados.

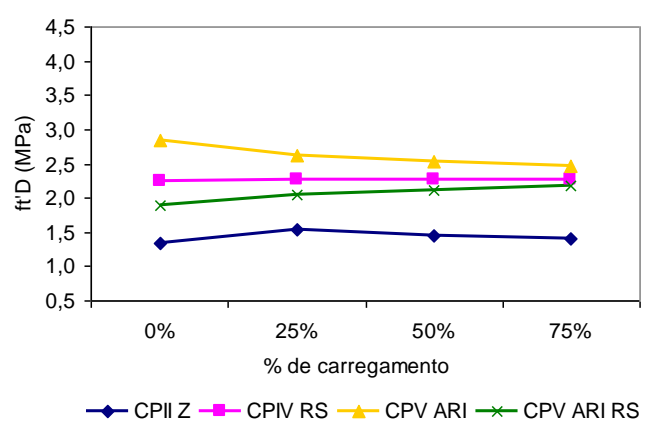

Figura 9 - Efeito isolado do percentual de pré-carregamento sobre a resistência à tração do concreto

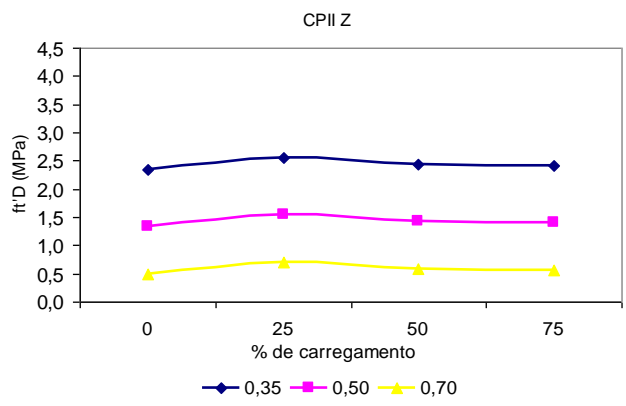

(a)

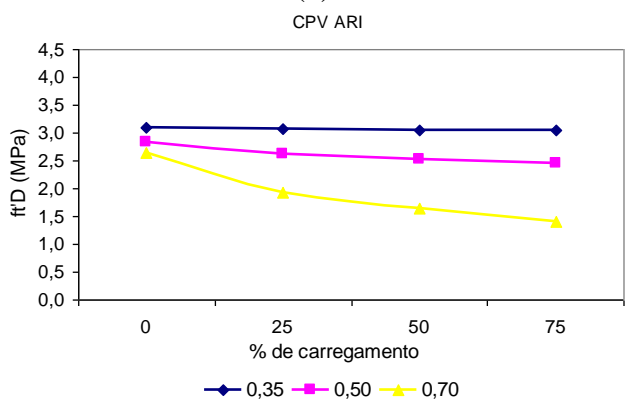

(c)

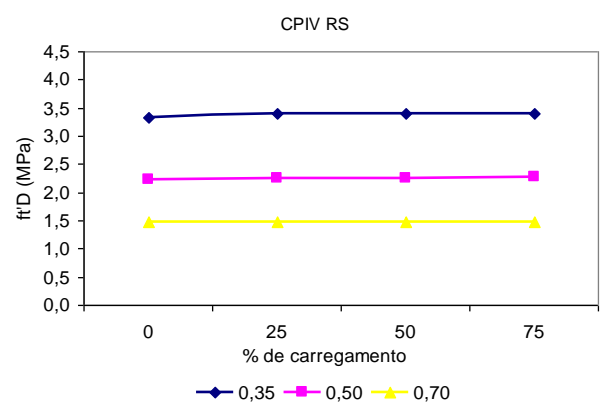

(b)

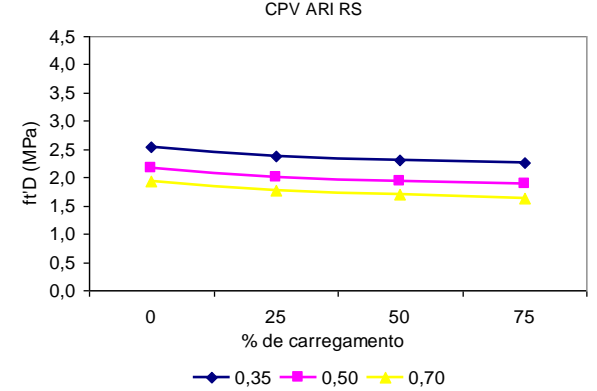

(d)

Figura 10 - Interação entre o percentual de pré-carregamento e relação a/c sobre a resistência à tração do concreto

Fonte: (a) CPII Z; (b) CPIV RS; (c) CPV ARI; (d) CPV ARI RS. 
Para relações a/c menores, os níveis de resistência à tração permanecem inalterados, ao contrário dos resultados de resistência à compressão. Em relações a/c maiores o grau de fissuração causado pelo pré-carregamento não possibilitou melhorias dessa propriedade. Com a aplicação da carga, a possível quebra dos cristais de hidróxido de cálcio não proporcionou melhora nos níveis de resistência à tração do concreto. A possível recuperação parcial de microfissuras formadas não é suficiente para manter os níveis de resistência à tração em patamares de referência (sem carregamento), pois se um número considerável de microfissuras é formado é necessário que todas sejam recuperadas para a manutenção dessa propriedade.

A interação entre o percentual de pré-carregamento e a idade de pré-carregamento também foi analisada. Os gráficos dessa interação podem ser visualizados na Figura 11.

A partir dos gráficos da Figura 11 pode-se observar que os concretos que foram précarregados em maiores idades tiveram maiores valores de resistência à tração. À medida que aumentava o percentual de carregamento,

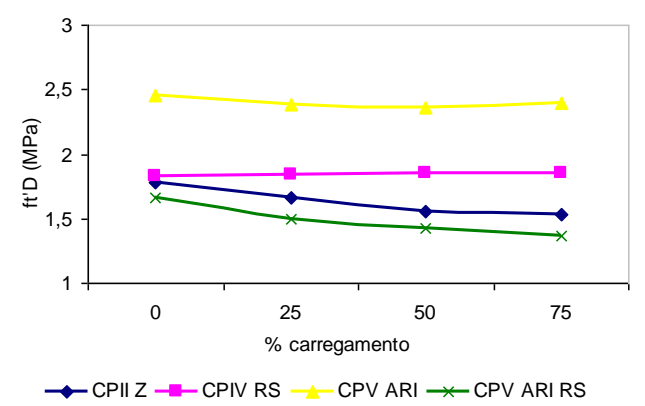

(a) diminuíam os valores de resistência à tração, para todos os cimentos estudados, exceto para o CPIV $\mathrm{RS}$, cujos valores permaneceram em patamares estáveis. Nos percentuais de $75 \%$ de carregamento, a perda de resistência à tração chega a $15 \%$, aproximadamente, em todas as idades de carregamento quando comparado aos valores de referência (sem carregamento).

Nessa configuração é possível verificar a influência do pré-carregamento na tração e podese, de alguma forma, relacionar a perda de resistência à tração com a formação e propagação de microfissuras, em função do carregamento precoce. Para Neville (1997), seria possível representar os critérios de fissuração e ruptura do concreto substituindo vários fatores atuando conjuntamente (cura, tipo de cimento, tensões atuantes) por um único parâmetro de resistência, tal como a resistência à tração uniaxial. Tal propriedade responde pelo desencadeamento de um processo de microfissuração na estrutura interna do concreto, especialmente na zona de transição.

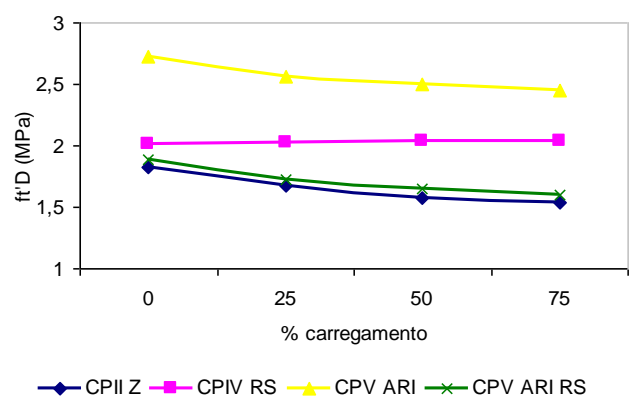

(b)

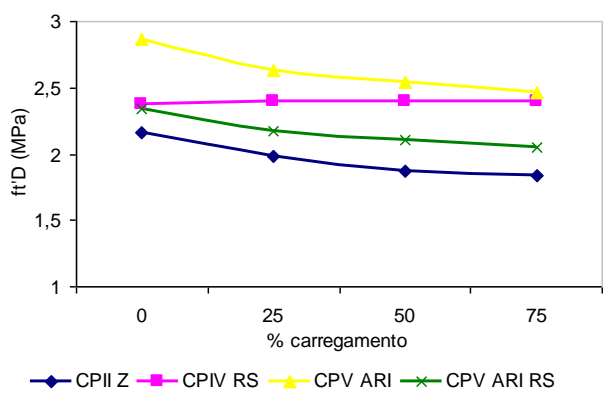

(c)

Figura 11 - Influência da interação entre o percentual de carregamento e a idade de carregamento sobre a resistência à tração dos concretos - (a) idade de carregamento de 1 dia; (b) 3 dias; e (c) 7 dias 


\section{Microestrutura do concreto submetido ao pré-carregamento}

Uma forma de constatar o processo de microfissuração é por meio da análise de imagens, obtidas pelo microscópio eletrônico de varredura. Essa técnica permite um maior entendimento da estrutura interna do concreto submetido a diferentes percentuais de carga. Assim, será possível observar o desenvolvimento e a propagação de microfissuras que podem ter se formado com a aplicação do carregamento. As análises foram realizadas no Centro de Microscopia da Universidade Federal do Rio Grande do Sul.

A detecção e visualização de microfissuras foi possível através da técnica de microscopia eletrônica de varredura, realizada em amostras de concreto com relação a/c de 0,5, idade de carregamento de 7 dias, percentual de précarregamento de $50 \%$ e para os cimentos CPV ARI e CPIV RS.

A Figura 12 apresenta diferentes pontos da zona de interface entre o agregado e a pasta. Para facilitar a visualização foram identificados três pontos da zona de transição e ampliado em 110 vezes o grau de detalhe da região. Também foi destacado em cor vermelha o delineamento da zona de interface entre o agregado graúdo e a pasta de cimento.

Nota-se, pela Figura 11, que não há presença de microfissuras na região de interface para os concretos de referência, ou seja, para as misturas produzidas com cimento CPV ARI que não receberam pré-carregamento.

A Figura 13 indica uma condição de microfissuração nas amostras que receberam $50 \%$ de pré-carregamento.

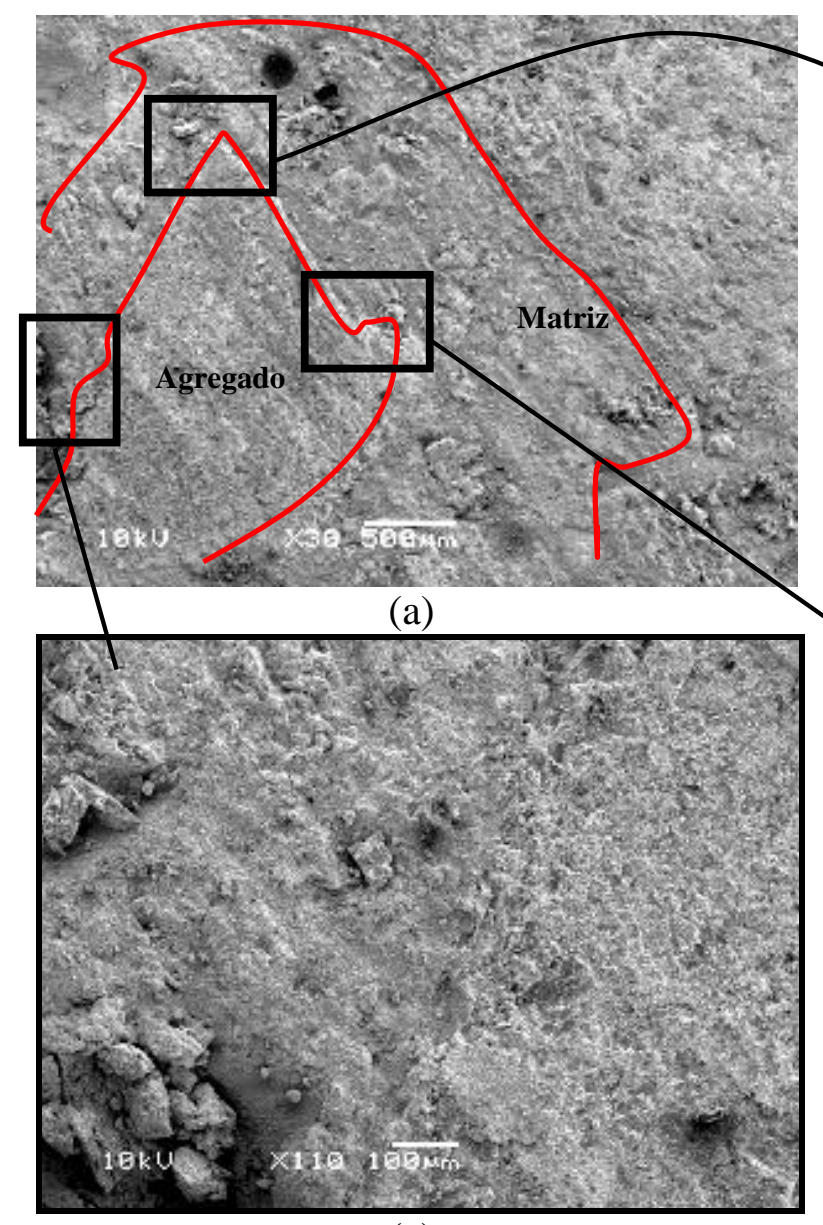

(c)

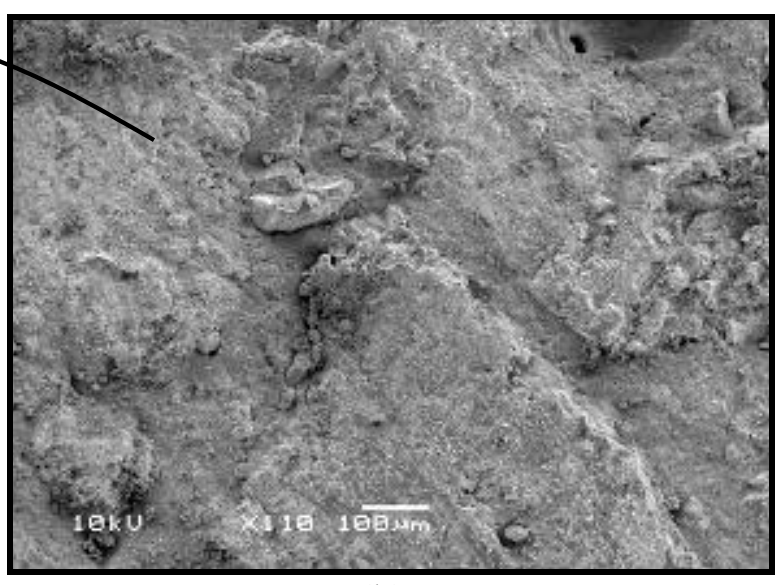

(b)

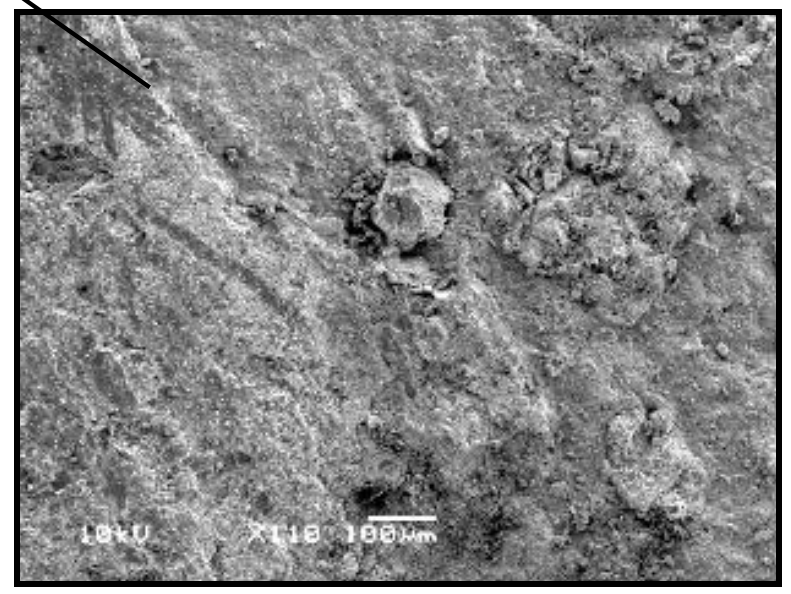

(d)

Figura 12 - Vista geral da interface pasta-agregado dos concretos de referência ampliada em 110 vezes 


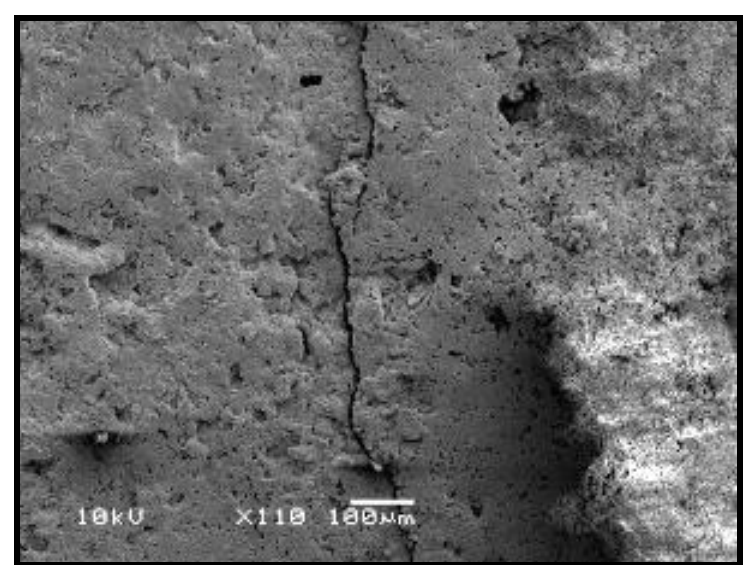

(a)

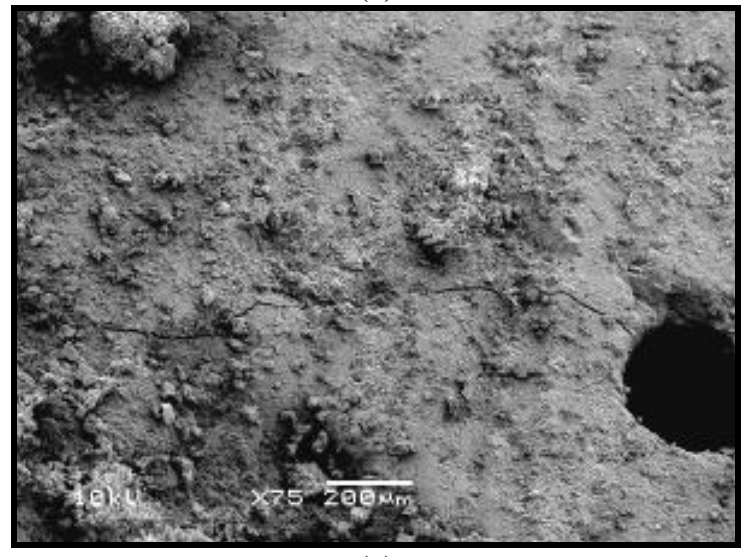

(c)

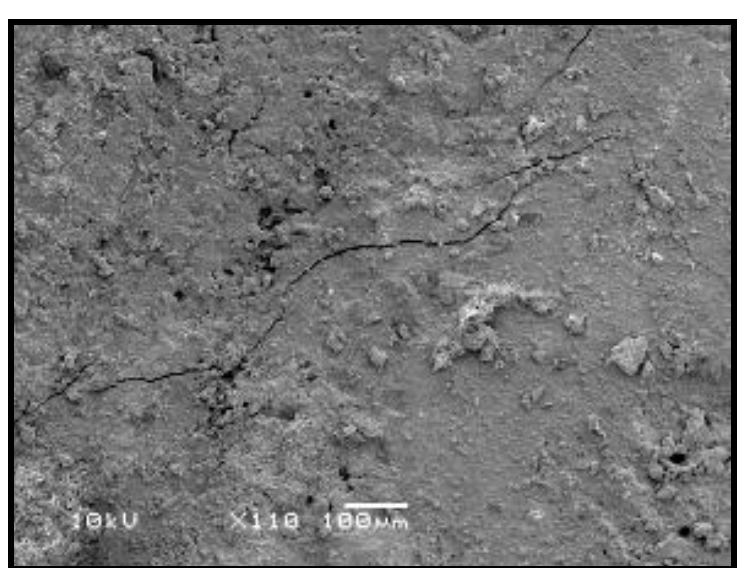

(b)

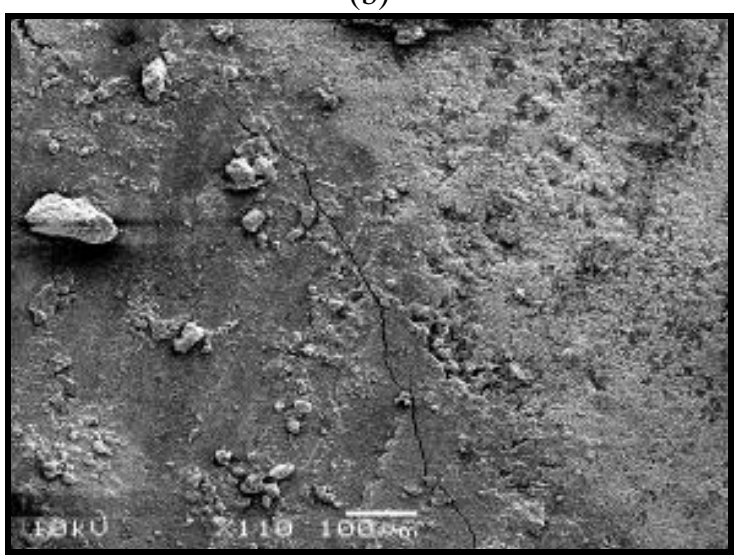

(d)

Figura 13 - Microfissuras causadas pelo carregamento precoce

Pela Figura 13 constata-se a presença de microfissuras nos concretos que receberam précarregamento de 50\%. O caminho das microfissuras parece seguir uma trajetória aleatória na pasta de cimento. Em regiões com presença de vazios as microfissuras tendem a procurar o caminho preferencial para dentro do poro (Figura 13c), por ser uma região de grande concentração de tensões (BARBIRATO, 1999). Os vazios presentes na argamassa favorecem a propagação das microfissuras. Por ser uma região fraca, sem ligação com outros compostos, a região que contém poros pode favorecer a formação de microfissuras. Com a aplicação de carregamento externo os poros tendem a se deformar em todas as direções, originando possíveis microfissuras decorrentes da concentração de tensões de tração nessa região.

Ao cessar o carregamento, possíveis microfissuras formadas tendem a se recuperar em função de as reações de hidratação do concreto ainda estarem relativamente no início. Neste trabalho, os corpos de prova retornavam ao ambiente de cura úmida após receberem a aplicação da carga, fato que pode ter colaborado para uma possível recuperação das ligações entre os compostos de cimentos que ainda não foram hidratados.

A Figura 14 apresenta micrografias dos concretos que receberam pré-carregamento aos 7 dias e logo após retornavam para a câmara úmida.

Pelas imagens apresentadas na Figura 14 pode-se verificar que houve recuperação das microfissuras causadas pelo carregamento precoce. Os concretos retornavam à câmara úmida e as partículas de água proveniente do ambiente de cura percolaram para o interior do corpo de prova, atingindo os interstícios formados pelas microfissuras, favorecendo a hidratação de compostos ainda não hidratados, que ficaram expostos com a abertura das microfissuras. Com isso, a água que permeou para o interior do concreto possibilitou a colmatação e a recuperação delas.

Esse comportamento foi verificado para o cimento CPV ARI. Dessa forma, constata-se que realmente ocorre a hidratação de produtos ainda não hidratados com a abertura das microfissuras, fato que contribui para a recuperação da resistência à compressão após receber diferentes percentuais de pré-carregamento. No entanto, apesar da característica de recuperação das microfissuras é 
possível observar que nem todas foram fechadas. Como mostra a Figura 14 (b, d, e), algumas microfissuras formadas não foram recuperadas, apesar das mesmas condições de cura. Nesse caso, as pontes de microfissuras não foram interrompidas, ou talvez não tenha percolado água suficiente para hidratar os compostos de cimento que ficaram expostos com a abertura da microfissura. Esse comportamento pode explicar o desempenho da resistência à tração, na qual não houve melhoria dessa propriedade com a aplicação da carga em diferentes percentuais.

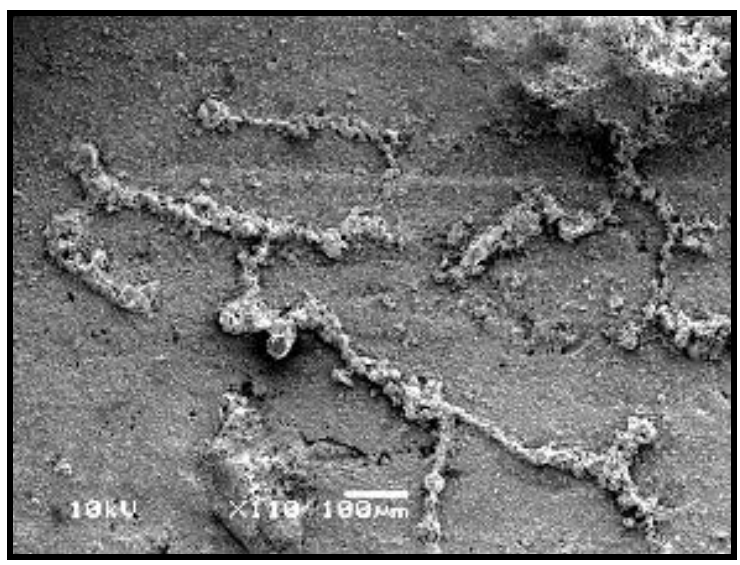

(a)

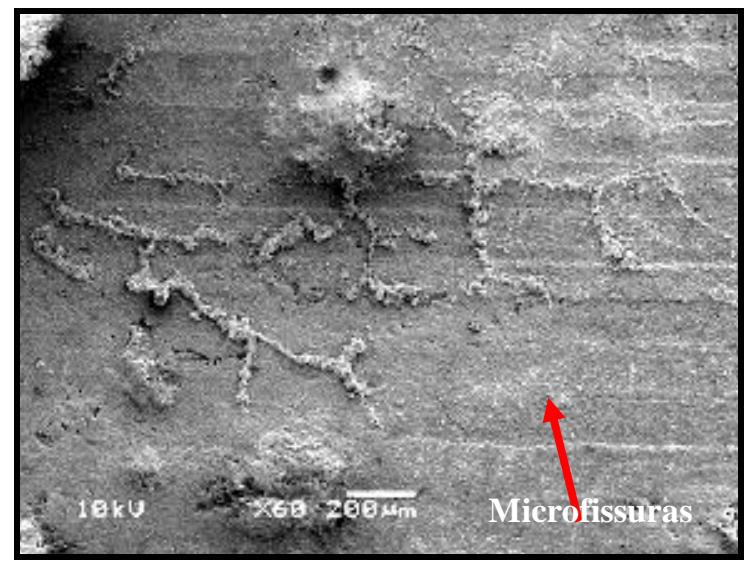

(b)

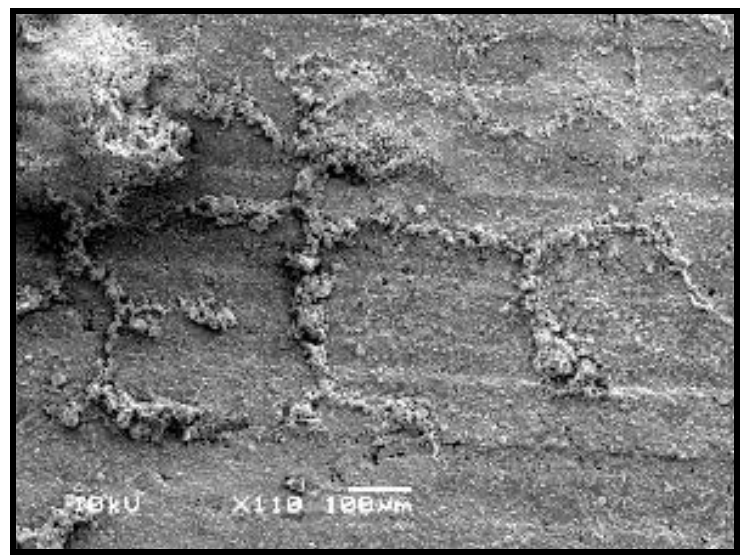

(d)

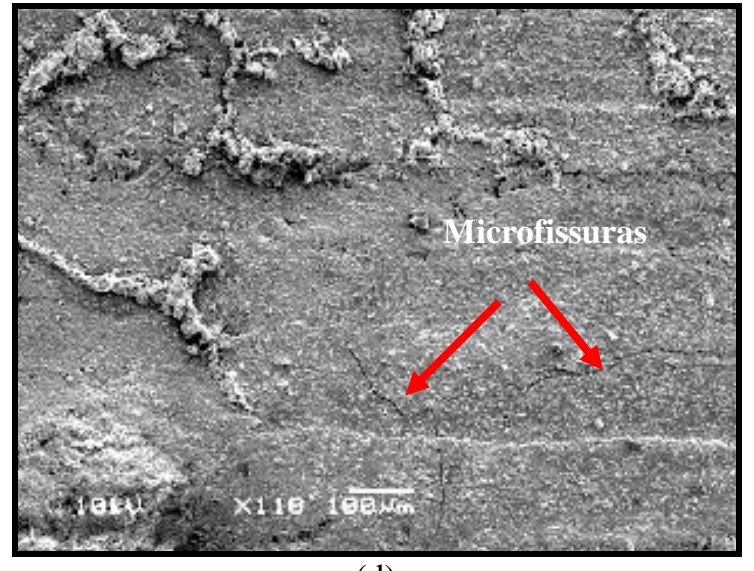

(d)

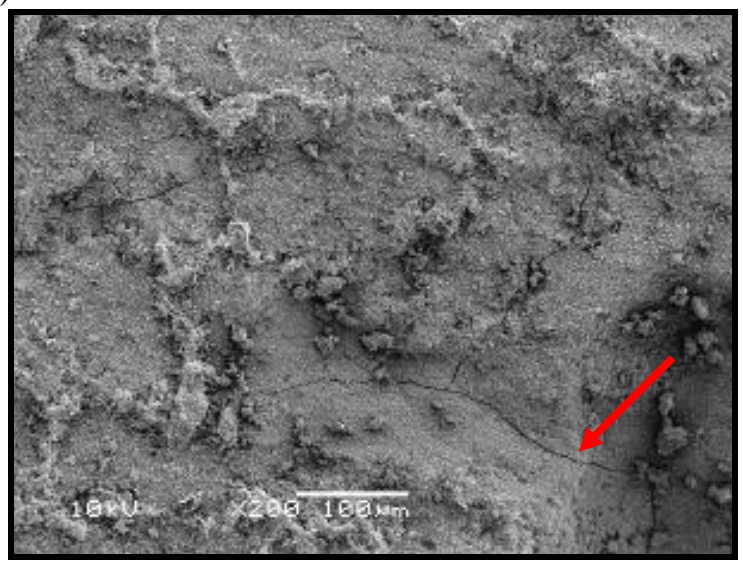

(e)

Figura 14 - Recuperação de microfissuras nos concretos que receberam pré-carregamento 


\section{Conclusões}

Pelo que foi exposto é possível explicar alguns comportamentos verificados ao longo do trabalho. Com os ensaios de microscopia foi possível detectar e visualizar um processo de microfissuração nos concretos pré-carregados. Além disso, a recuperação das microfissuras verificadas corrobora a teoria de que ocorre colmatação autógena, quebra de cristais mais fracos e hidratação de compostos resistentes remanescentes, melhorando os valores da propriedade de resistência à compressão. No entanto, essa recuperação não é completa, fato que foi comprovado na visualização de microfissuras não recuperadas, o que pode ter influenciado negativamente nos resultados de resistência à tração.

De uma forma geral, os resultados puderam comprovar a existência de um processo de microfissuração causado pela ação de um carregamento precoce nos concretos com pouca idade. Tal fato remete a um problema citado no início deste trabalho: as ações de construção decorrentes de um processo acelerado de execução de uma edificação devem ser consideradas. Apesar do bom desempenho em relação à resistência à compressão, os valores da resistência à tração foram prejudicados de alguma forma com a aplicação do carregamento.

A adoção de medidas simples como o respeito aos prazos de cura, hidratação e evolução da resistência do concreto e, principalmente, como respeito às exigências normativas reduziria sensivelmente os problemas decorrentes dessas ações, além do aprimoramento das técnicas construtivas utilizadas. Esses procedimentos poderiam minimizar a formação de microfissuras no concreto, a baixa resistência à entrada de agentes agressivos, a baixa resistência mecânica de tração. Com isso, a resposta da estrutura a essas ações indevidas, ainda na fase de construção, seria a redução do surgimento de manifestações patológicas dessa natureza.

\section{Referências bibliográficas}

AITCIN, P. C. Concreto de Alto Desempenho. Tradução de Geraldo Serra. São Paulo: PINI, 2000. $667 \mathrm{p}$.

ASSOCIAÇÃO BRASILEIRA DE NORMAS TÉCNICAS. NBR 5739: concreto: ensaio de compressão de corpos-de-prova cilíndricos: método de ensaio. Rio de Janeiro, 1994.
ASSOCIAÇÃO BRASILEIRA DE NORMAS

TÉCNICAS. NBR 5738: procedimento para

moldagem de corpos de prova de concreto. Rio de Janeiro, 2003.

\section{ASSOCIAÇÃO BRASILEIRA DE NORMAS}

TÉCNICAS. NBR 7222: argamassa e concreto: determinação da resistência à tração por compressão diametral de corpos-de-prova cilíndricos. Rio de Janeiro, 1994.

\section{ASSOCIAÇÃO BRASILEIRA DE NORMAS}

TÉCNICAS. NBR 14931: execução de estruturas de concreto: procedimento. Rio de Janeiro, 2003.

BARBIRATO, J. C. C. Método dos Elementos Finitos de Contorno com a Reciprocidade Dual para a Análise Transiente Tridimensional da Mecânica do Fraturamento. 1999. 270 f. Tese (Doutorado em Engenharia Civil) - Escola de Engenharia de São Carlos, Universidade de São Paulo, São Carlos, 1999.

\section{BOTTA, A. S. Cálculo de Esforços e}

Deslocamentos em Estruturas Reticuladas Considerando-se a Mecânica do Dano para a Modelagem do Concreto Armado. 1998. 119 f. Dissertação (Mestrado em Engenharia Civil) Escola de Engenharia de São Carlos. Universidade de São Paulo, São Carlos, 1998.

BURLION, N.; BOURGEOIS, F.; SHAO, J. F. Effects of Desiccation on Mechanical Behavior of Concrete. Cement \& Concrete Composites, v. 27, n. 3, p. 367-379, 2005.

CARPINTERI, A.; CHIAIA, B.; NEMATI, K. M. Complex Fracture Energy Dissipation in Concrete Under Different Loadings Conditions. Mechanical of Materials, v. 26, n. 2, p. 93-108, 1997.

ELAQRA, H. et al. Damage Evolution Analysis in Mortar, During Compressive Loading Using Acoustic Emission and X-Ray Tomography: effects of the sand/cement ratio. Cement \& Concrete Research, v. 37, n. 4, p. 703-713, 2007.

FRANÇA, R. L. S. Fatores Críticos de Execução de Obras e as Consequiências para as Deformações de Estruturas de Concreto. In: SEMINÁRIO DE TECNOLOGIA DE ESTRUTURAS, 7., São Paulo. 2005. Anais... São Paulo, 2005.

KANG, W. T.; BITTENCOURT, T. N. Identificação de Processo de Fraturamento no Concreto Estrutural. Caderno de Engenharia da Escola de Engenharia de São Carlos, São Paulo, 1999.

LANDIS, E. N.; NAGY, E. N.; KEANE, D. T. Microestructure and Fracture in Three Dimensions. Enginnering Fracture Mechanics, v. 70, n. 7, p. 911-925, 2003. 
MAZARS, J.; BAZANT, Z.P. Cracking and Damage: strain localization and size effect. In: FRANCE-US WORKSHOP ON STRAIN LOCALIZATION AND SIZE EFFECT DUE TO CRACKING AND DAMAGE. Cachan, 1988. Proceendings... Londres: Elsevier Applied Science, 1989.

MEDEIROS, H. Alerta! Deformações Excessivas: edifícios expõem patologias de todo tipo, principalmente na alvenaria. Por que as estruturas estão deformando como nunca? 2005. Disponível em: <http://www.piniweb.com.br> Acesso em: 25 maio 2006.

METHA, P. K.; MONTEIRO, P. J. M. Concreto: estrutura, propriedades e materiais. São Paulo: PINI, 1994. 573 p.

NEVILle, A. M. Propriedades do Concreto. Tradução de Salvador E. Giammusso. 2. ed. São Paulo: PINI, 1997. 828 p.

PITUBA, J. J. C. Sobre a Formulação de um Modelo de Dano para o Concreto. São Carlos, 2003. 189 f São Carlos. Tese (Doutorado em Engenharia Civil) - Escola de Engenharia de São Carlos, Universidade de São Paulo, São Carlos, 2003.
PRADO, J. F. M. A. Estruturas de Edifícios em Concreto Armado Submetidas a Ações de Construção. 1999. 201 f. São Carlos. Tese (Doutorado em Engenharia Civil) - Escola de Engenharia de São Carlos, Universidade de São Paulo, São Carlos, 1999.

REDA, M. M.; SHRIVE, N. G.; GILLOTE, J. E. Microstructural Investigation of Innovative UHPC. Cement \& Concrete Research, v. 29, p. 323-329, 1999.

SANTOS, A. C.; SOUZA, J. L. A. O.; BITTENCOURT, T. N. Determinação da Tenacidade ao Fraturamento do Concreto com Corpos de Prova do Tipo "Short-Rod". Cadernos de Engenharia de Estruturas da Escola de Engenharia de São Carlos, São Paulo, 2003.

\section{Agradecimentos}

Os autores agradecem ao Conselho Nacional de Desenvolvimento Científico e Tecnológico (CNPq) pela concessão da bolsa, sem a qual esta pesquisa não teria sido realizada.

Revista Ambiente Construído

Associação Nacional de Tecnologia do Ambiente Construído

Av. Osvaldo Aranha, $99-3^{\circ}$ andar, Centro

Porto Alegre - RS - Brasil CEP $90035-190$

Telefone: +55 (51) 3308-4084

Fax: +55 (51) 3308-4054

www.seer.ufrgs.br/ambienteconstruido

E-mail: ambienteconstruido@ufrgs.br 